\title{
ВЗАИМОСВЯЗЬ КАРИОЗНЫХ ПОРАЖЕНИЙ У ДЕТЕЙ ДО З ЛЕТ СО СТЕПЕНЬЮ ГИПОКСИИ ПЛОДА
}

\section{RELATIONSHIP OF CARIOSIS IN CHILDREN UNDER3 YEARS OLD WITH THE DEGREE OF FETAL HYPOXIA}

\section{O. Makarchuk}

Summary. There are a number of studies aimed at studying the negative effect of pregnancy complications on the formation and further development of the dento-jaw system of the fetus. The paper considers the relationship between the degree of hypoxia and carious lesions in children under the age of 3 years. It was found that in children who had a pronounced degree of hypoxia in utero, carious spots were 1.5-2 times more common, and their area and density of carious spots were greater than in children who had a moderate degree of hypoxia in utero. This dictates the need to develop specialized measures aimed at early diagnosis and timely therapy of fetal hypoxia.

Keywords: fetal hypoxia, carious lesions, dental-jaw system, children, carious spots, pregnancy.

\section{Введение}

A ктуальной проблемой детской стоматологии является терапия кариеса и его осложненных форм как молочных, так и постоянных зубов. Наиболее остро данная проблема стоит в возрастной группе с рождения до 3-х лет. Первые признаки кариесогенного поражения зубов в ряде случаев обнаруживают уже на этапе прорезывания молочных зубов [1]. Кариес молочных зубов, как и гипоплазия твердых тканей молочных зубов, в возрастной группе от рождения до 3-х лет в преимущественном количестве случаев является следствием нарушения первичной минерализации твердых тканей в ходе антенатального и постнатального периодов [2].

К сегодняшнему дню проведен ряд исследований, посвященных изучению отрицательного действий осложнений в ходе беременности женщины на формирование и развитие зубо-челюстной системы (3ЧС) плода. Большая часть работ посвящена развитию кариесогенных поражений, так как они являются наиболее распространёнными среди детского населения $[3,4,5]$.
Макарчук Ольга Анатольевна Ассистент, Кировский государственный медииинский университет; заведующий отделением, врач-стоматолог детский, КОГБУз «Кировский клинический стоматологический центр» olgamakarchuk79@mail.ru

Аннотация. Имеется ряд исследований, направленных на изучение отрицательного влияния осложнений беременности на формирование и дальнейшее развитие зубочелюстной системы плода. В работе рассмотрена взаимосвязь между степенью гипоксии, перенесённой внутриутробно и кариозными поражениями у детей в возрасте до 3-х лет. Было выявлено, что у детей, которые имели внутриутробно выраженную степень гипоксии, в 1.5-2 раза чаще распространены кариозные пятна, а также площадь и плотность кариозных пятен у них была больше по сравнению с детьми, которые имели внутриутробно умеренную степень гипоксии. Это диктует необходимость разработки специализированных мер, направленных на раннюю диагностику и своевременную терапию гипоксии плода.

Ключевые слова: гипоксия плода, кариозные поражения, зубочелюстная система, дети, кариозные пятна, беременность.

Выявлено, что появление и развитие кариеса у детей обусловлены следующими состояниями:

- Перенесенные острые или обострение хронических заболеваний у матери во время беременности;

- Осложнения беременности, в том числе гипоксия плода различной степени;

- Ранний отказ от естественного и перевод на искусственное вскармливание;

- Заболевания, перенесенные в период новорожденности;

- Осложнения во время родов;

- Нарушения таких базовых навыков как жевание, дыхание и глотание в ходе раннего развития ребенка;

- Ослабление иммунологической устойчивости организма;

- Инфекционные заболевания, перенесенные как матерью во время беременности, так и самим ребенком;

- Потребление воды с низким содержанием фторидов;

- Генетические аномалии. 
Из перечисленных причин первые две являются наиболее распространёнными и имеют серьезные негативные последствия [6].

Анализ литературных источников доказал неблагоприятное влияние поздних токсикозов матери на поздних сроках беременности, которые сопровождались артериальной гипотензией, на формирование и развитие зубочелюстной системы плода. Изучение механизма влияния системных нарушений артериального давления и патологий системы кровообращения, в том числе гипоксии, в течение антенатального периода развития на закладку и развитие тканей зубочелюстной системы плода дает возможность определить и описать патогенетические механизмы кариеса в ходе дальнейшего онтогенеза ребенка $[7,8,9,10]$.

Таким образом, гипоксия плода является одним из основных кариесогенных факторов. Это наиболее клинически значимый стресс, которому подвергается плод и новорожденный. Причины гипоксии разнообразны. Гипоксия отрицательно сказывается на генезе органов и тканей всего организма плода в целом и зубочелюстной системы в частности. Состояние кислородного голодания оказывает воздействие на эмбриогенез тканей зубов, а также на уровень жизни детей до 3 лет, в частности происходит гипоминерализация зубов, что в разы повышает вероятность развития кариозных поражений [11]. Однако на сегодняшний день эффекты, оказываемые гипоксической средой, и механизмы их реализации изучены недостаточно хорошо.

\section{Цель исслемования}

Выявить и обосновать взаимосвязь степени и распространенности кариозных поражений временных зубов у детей возрастной группы до 3-х лет и степени тяжести гипоксии, перенесенной внутриутробно.

\section{материалы и методы}

Для реализации поставленной цели исследования использовались следующие методы: контент-анализ, ретроспективный анализ, наблюдение, индукция, сравнительный анализ.

Были обследованы дети, имеющие в анамнезе выраженную и умеренную внутриутробную гипоксию плода, отображённую в выписке из истории развития новорождённого и протоколе ультразвукового исследования структур головного мозга. Осмотрено 50 человек: 30 детей, имеющие выраженную степень внутриутробной гипоксии (по шкале Апгар на 1-й минуте жизни 4-5 баллов) и 20 с умеренной степенью (по шкале Апгар на 1-й минуте жизни 6-7 баллов) гипоксии в анамнезе. Дети с выражен- ной гипоксией плода были осмотрены 3 раза на протяжении исследования, в возрасте: 6 месяцев, 1 год, 1.5 года и 2 года. Дети, имеющие в анамнезе умеренную внутриутробную гипоксию так же. Диагностика была проведена методом стоматологического осмотра с помощью зонда и зеркала, также проводилось витальное окрашивание кариозных пятен 2\% водным раствором метиленового синего. У всех детей были определены следующие параметры:

- Индекс КПУ (з). Это сумма кариозных, пломбированных и удаленных зубов у одного ребенка.

- Индекс КПУ (п). Это сумма всех поверхностей зубов, на которых был выявлен кариес

- Цвет выявленных кариозных пятен.

- Границы и плотность выявленных кариозных пятен.

- Площадь поверхности выявленных кариозных пятен. Для измерения площади использовалась линейка.

\section{Результаты}

Было выявлено, что у детей с выраженной степенью гипоксии распространенность кариеса увеличивалась в процессе взросления. Таким образом, в возрасте 6 месяцев в среднем составил КПУ(з) - 2, КПУ(п) - 3. В возрасте 1 года: КПУ(з) - 4, КПУ(п)- 8. У детей 1.5 лет КПУ(з) также равняется 4, КПУ(п) - 8. Индекс КПУ(3) осмотренных детей в возрасте 2 лет увеличился и составил в среднем 6, КПУ (п) - 8 .

Индекс КПУ (з) у детей, имеющих умеренную степень гипоксии, в возрасте 2 лет в среднем равен 4, КПУ(п) = 8 .

Среди детей с выраженной степенью гипоксии во внутриутробном состоянии кариозные пятна визуализируются у 76.7\% осмотренных детей, остальные 23,3\% являются здоровыми.

Среди детей с умеренной степенью гипоксии во внутриутробном состоянии были дети, не имеющие пятна 55\%, и 45\% детей, у которых были вывялены кариозные поражения.

При осмотре детей с выраженной степенью гипоксии во внутриутробном состоянии выявляется от 1 до 6 кариозных пятнен на зубах 5.4, 5.3, 5.2, 5.1, 6.1, 6.2, 6.3, 7.3, 8.3, что соответствует периоду первичной минерализации денных зубов во внутриутробном развитии в период гипоксии плода. Кариозные пятна визуализируются у $76.7 \%$ осмотренных детей, остальные $23.3 \%$ являются здоровыми. Пятна встречаются на центральных резцах $(5.1,6.1)$ у $69.6 \%$ детей, на латеральных резцах $(5.2,6.2)-$ $39.1 \%$ соответственно. У $21.7 \%$ осмотренных, выявлены кариозные пятна на клыках верхней челюсти $(5.3,6.3)$, у $8.7 \%$ осмотренных на клыках нижней челюсти $(7.3,8.3)$. 
При осмотре детей с умеренной степенью гипоксии во внутриутробном состоянии также чаще кариозные пятна были вывялены на верхних центральных резцах (55\% случаев), реже на верхних латеральных резцах у $33 \%$ детей, и у $12 \%$ детей кариозные поражения визуализировались на верхних клыках.

Кариозные поражения у детей с умеренной и выраженной степенью гипоксии во внутриутробном состоянии были выявлены в пришеечной области. Пятна, выявленные на резцах верхней челюсти, встречаются чаще, это обусловлено ранней минерализацией (на 4,5 месяце внутриутробного развития) и ранним прорезыванием (центральные резцы - 6.8 месяцев, латеральные - 8.12 месяцев).

Кариозные пятна у детей с выраженной степенью гипоксии во внутриутробном состоянии чаще визуализируются в стадии белого пятна (91\% детей), коричневые пятна у 13\% детей, также у 1 ребенка были выявлены серые пятна на клыках обеих челюстей.

Кариозные пятна у детей с умеренной степенью гипоксии во внутриутробном состоянии также чаще встречаются в стадии белого пятна (66\% детей), реже серого и коричневого цвета - $22 \%$ и $22 \%$ процента соответственно.

У детей с выраженной степенью гипоксии во внутриутробном состоянии по плотности чаще визуализировались пятна, имеющие шероховатую поверхность (70\%), реже - плотные (30\%).

У детей с умеренной степенью гипоксии во внутриутробном состоянии по плотности были выделены пятна, имеющие шероховатую поверхность (55\% случаев) и плотные (45\%).

Площадь пятен у детей с выраженной степенью гипоксии во внутриутробном состоянии варьировалась от 0.8 мм $^{3}$ до 1.2 мм³ $^{3}$ В $61 \%$ случаев кариозные пятна имеют площадь $1 \mathrm{~mm}^{3}$, у 10\% осмотренных $0.8 \mathrm{~mm}^{3}$, и у $29 \%-1.2 \mathrm{~mm}^{3}$.

Площадь пятен у детей с умеренной степенью гипоксии во внутриутробном состоянии также варьировалась

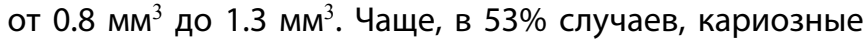

пятна имеют площадь 1.3 мм³ $^{3}$, реже, у 29\% осмотренных - 1 мм $^{3}$, и у $18 \%$ площадь пятна составила 0.8 мм³. $^{3}$.

\section{Выво $\triangle ы$}

Проведенное исследование показало, что дети, имеющие выраженную гипоксию во внутриутробном состоянии, в 1.5-2 раза чаще имеют кариозные пятна по сравнению с детьми, которые имели умеренную степень гипоксии. Помимо этого, было выявлено, что:

- КПУ (з) у детей с выраженной гипоксией в 1.3 раза выше, чем у детей с умеренной гипоксией, при этом КПУ (п) одинаковы.

- Кариозные пятна у детей с выраженной гипоксией обнаруживаются чаще в 1.7 раза.

- Чаще у всех осмотренных детей поражаются центральные резцы (в среднем (62\%), реже латеральные (36\%), и ещё реже - клыки (19\%). Дети с выраженной гипоксией имеют большую степень поражения - в 2 раза.

- У обследованных детей пятна чаще обнаруживаются в стадии белого пятна (78\% детей в среднем), коричневые - 24\%, серые - $18 \%$. У детей с выраженной степенью гипоксии этот показатель так же выше - в 1.7 раз.

- По плотности чаще встречаются пятна, имеющие шероховатую поверхность, у всех осмотренных детей - 57\% случаев, реже - плотные - 52\%. У детей с выраженной гипоксией этот показатель выше в 1.4 раза.

- Площадь пятен в среднем у всех детей $1 \mathrm{~cm}^{3}$. Этот показатель у детей с выраженной гипоксией, наоборот, ниже - пятна у детей с выраженной гипоксией чаще встречаются от $0.8 \mathrm{~cm}^{3}$ до $1 \mathrm{~cm}^{3}$, а у детей с умеренной степенью гипоксии от $1 \mathrm{~cm}^{3}$ до $1.3 \mathrm{~cm}^{3}$.

Полученные сведения позволяют сделать вывод о наличии связи между степенью гипоксии, перенесенной плодом внутриутробно, и кариозными поражениями детей до 3-х лет. В связи с этим, дети, которые внутриутробно страдали от гипоксии выраженной степени находятся в группе повышенного риска развития кариозных поражений. Это диктует необходимость разработки для них комплекса диагностических и профилактических мероприятий, направленного на предупреждение и раннюю диагностику.

\section{ЛИТЕРАТУРА}

1. Сайфуллина Х.М. Кариес зубов у детей и подростков /Х.М. Сайфуллина.—- М., 2000. — 95 С.

2. Виноградова Т.Ф. Диспансеризация детей у стоматолога /Т.Ф. Виноградова. - М., 1988. — 250 c.

3. Frasch M.G., Giussani D.A. Cells. Impact of Chronic Fetal Hypoxia and Inflammation on Cardiac Pacemaker Cell Development. 2020 Mar 17;9(3):733. doi: 10.3390/ cells 9030733 . 
4. Ducsay C.A., Goyal R., Pearce W.J., Wilson S., Hu X.Q., Zhang L. Physiol Rev. Gestational Hypoxia and Developmental Plasticity. 2018 Jul 1;98(3):1241-1334. doi: 10.1152/physrev.00043.2017.

5. Wood C.E., Keller-Wood M. Am J Physiol Regul Integr Comp Physiol. Current paradigms and new perspectives on fetal hypoxia: implications for fetal brain development in late gestation. 2019 Jul 1;317(1): R1-R13. doi: 10.1152/ajpregu.00008.2019.

6. Корчагина В.В. ФАКТОРЫ РИСКА РАЗВИТИЯ КАРИЕСА // Медицинская сестра. 2017. № 7. URL: https://cyberleninka.ru/article/n/faktory-riska-razvitiya-kariesa (дата обращения: 09.04.2021).

7. Калоева 3.Д., Дзгоева М.Г. Особенности стоматологического статуса у детей с врожденными сосудистыми дистониями. Сб. тез. науч. тр. СогмА. Владикавказ, 2011: 56.

8. Лебеденко И.Ю., Ковалев Ю.С., Малый А.Ю. Сб. научных трудов «Современные проблемы стоматологии» к 70-летию В.Н. Копейкина. М.: ММСИ, 1999: $11-12$.

9. Кречина Е.К. Симпозиум «Лазеры в стоматологии». М., 2000: 78-80.

10. Калоева 3.Д. Особенности первичной артериальной гипотензии у детей. Автореф. дисс. докт. мед. наук. М., 1994: 35.

11. Дзгоева М.Г. Особенности формирования и развития зубочелюстной системы у детей при наличии фоновой патологии системной гемодинамики // Педиатрия. Журнал им. Г.Н. Сперанского. 2007. № 6. URL: https://cyberleninka.ru/article/n/osobennosti-formirovaniya-i-razvitiya-zubochelyustnoy-sistemy-u-deteypri-nalichii-fonovoy-patologii-sistemnoy-gemodinamiki (дата обращения: 08.04.2021).

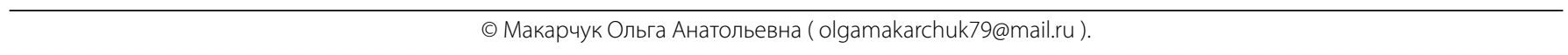

Журнал «Современная наука: актуальные проблемы теории и практики»

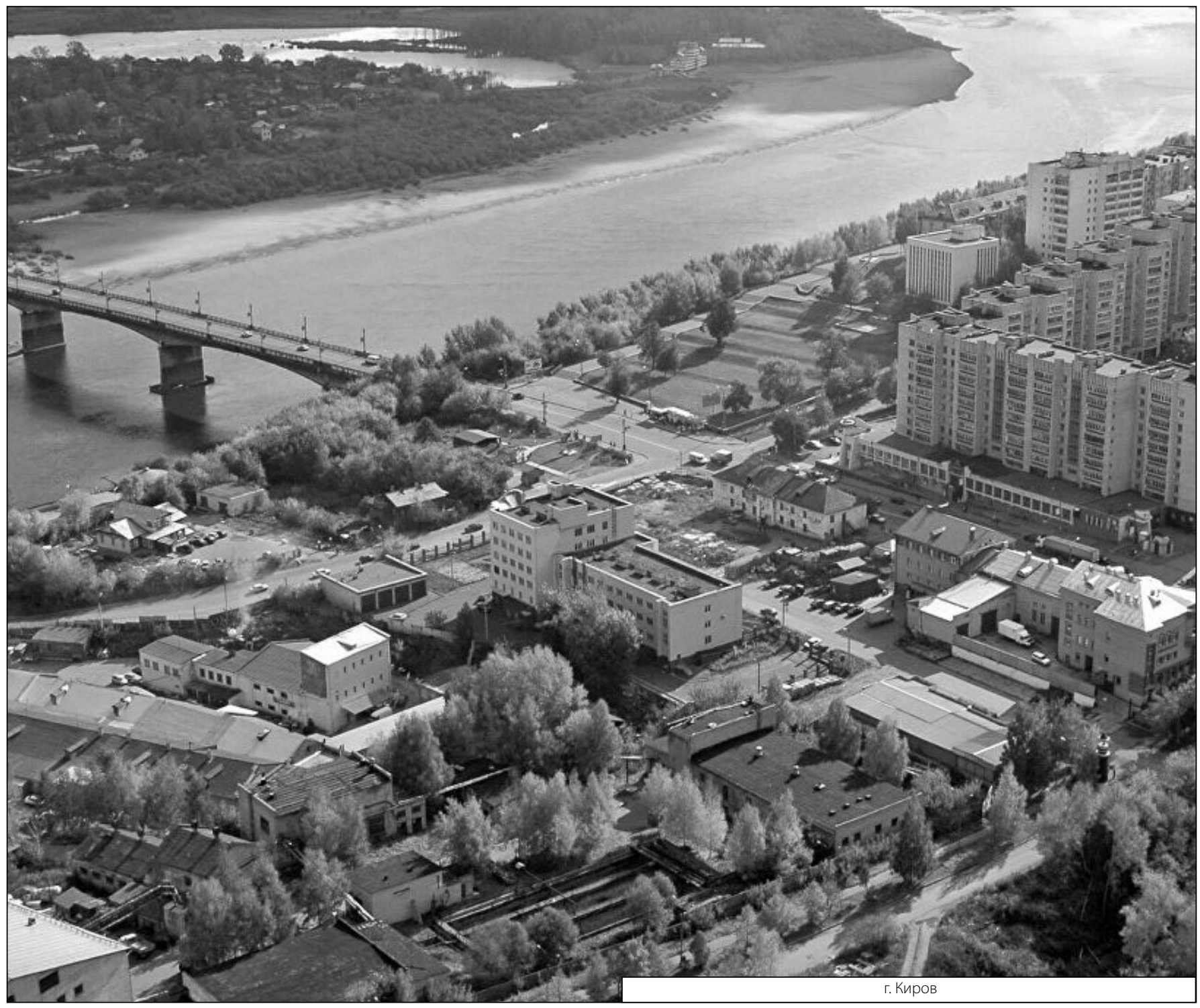

